\title{
Contribuições da Psicologia à educação escolar: perpetuação ou transformação das desigualdades sociais?
}

Vera Lucia Trevisan de SOUZA' 1 [D] 0000-0003-2062-0680

\section{Resumo}

Este artigo discute o papel da escola na constituição dos sujeitos, aborda suas contribuições ao desenvolvimento ou à inibição dele, a depender das interações das quais participam os alunos, e insere a escola no contexto mais amplo da sociedade, considerando os múltiplos fatores que a constituem como instituição que, a um só tempo, conserva e transforma valores, saberes e diversas práticas culturais e que emperra processos de desenvolvimento de crianças, adolescentes e adultos. Reflete, então, sobre a escola como produtora de desigualdade, por um lado, e promotora da superação das condições de existência, por outro. Busca-se destacar o papel da escola como fomentadora da consciência dos sujeitos sobre si e sobre o mundo, sobre as condicionantes de suas vidas atuais e possibilidades futuras.

Palavras-chave: Desigualdade educacional; Psicologia cultural; Psicologia escolar.

O presente artigo, de caráter reflexivo, resulta de estudos, pesquisas e discussões desenvolvidas por um grupo de pesquisa no âmbito da Pós-Graduação em Psicologia e aborda a escola e seu papel no desenvolvimento de crianças e adolescentes sob o olhar da Psicologia Escolar/Educacional, inserindo-a como instituição privilegiada na circulação dos bens produzidos pela cultura. Intenta problematizar a complexidade do espaço escolar como cenário que viabiliza encontros e desencontros entre os sujeitos que interagem e se constituem em seu interior.

Compreende-se as relações escolares como um processo interativo, cujos significados e sentidos são constantemente reinterpretados na construção da realidade concreta da escola. Essa perspectiva assume a educação como processo dinâmico e negociado, que constitui as ações dos diferentes atores escolares, na produção dos valores, das crenças e dos princípios que pautam o cotidiano escolar. Como instituição de direito de todos os cidadãos brasileiros, a escola, sobretudo a da rede pública, que atende a maioria das crianças e jovens do país, depara com desafios cotidianos relativos a tensões produzidas por uma multiplicidade de fatores. Esses se apresentam como demandas às suas ações, dentre as quais, a diversidade de histórias, conhecimentos, princípios e valores que portam os professores, gestores, alunos e comunidade, e as condições materiais em que desenvolve a educação escolarizada, produzida pelas políticas públicas que se alternam periodicamente, mantendo-se com as características de políticas de governo e não de Estado.

$\nabla \nabla \nabla v$

1 Pontifícia Universidade Católica de Campinas (PUC-Campinas), Centro de Ciências da Vida, Programa de Pós-Graduação em Psicologia. Av. John Boyd Dunlop, s/n., 13060-904, Jd. Ipaussurama, Campinas, SP, Brasil. E-mail: <vera.trevisan@uol.com.br>.

$\boldsymbol{\nabla} \mathbf{\nabla} \boldsymbol{\nabla}$

Como citar este artigo

Souza, V. L. T. (2022). Contribuições da Psicologia à educação escolar: perpetuação ou transformação das desigualdades sociais? Estudos de Psicologia (Campinas), 39, e200178. https://doi.org/10.1590/1982-0275202239e200178 


\section{A escola pública brasileira: promotora de desenvolvimento ou produtora de desigualdade?}

Com base nos pressupostos da Psicologia Histórico-Cultural, temos defendido o potencial da escola na promoção do desenvolvimento de Funções Psicológicas Superiores que favorecem o pensamento complexo, capaz de ampliar as significações do mundo pelo sujeito. Por esta via esse sujeito passa a dominar modos de pensar mais elaborados e formas de linguagem que se imbricam na produção de significações, mobilizadas por processos imaginativos que resultam em potência de ação. É nesse sentido que a escola pode se constituir como promotora da superação das desigualdades, por vezes creditada somente às diferenças de renda entre os indivíduos. Para Arretche (2015), a desigualdade se relaciona à condição de acesso aos bens e serviços de uma sociedade, correspondendo ao direito do indivíduo a uma vida digna de modo a poder expandir sua liberdade. Esses direitos não seriam redutíveis à renda, ou seja, todos os cidadãos, em uma sociedade igualitária, teriam acesso aos serviços essenciais. Logo, considerar a desigualdade presente na escola implica abordar suas multideterminações (Souza, 2019).

Quer-se destacar, neste artigo, o papel da escola não na formação de indivíduos para o mercado de trabalho (como está previsto nas novas políticas educacionais, notadamente na Base Nacional Curricular (Comum) ${ }^{2}$, na dimensão que a coloca a serviço do capital. Ao contrário, quer colocá-la como fomentadora da consciência dos sujeitos que a habitam, sobre si e sobre o mundo, sobre as condicionantes de suas vidas atuais, ou seja, o domínio do conhecimento, da história desse conhecimento e sua apropriação é que promoverá a visualização das possibilidades de futuro.

\section{A escola como fomentadora do desenvolvimento dos sujeitos}

Desde muito cedo, a apropriação da cultura humana pela criança se caracteriza como um processo contínuo e progressivo, que promove o desenvolvimento de suas funções psicológicas rumo a uma complexidade cada vez maior, pela assunção ao caráter de mediada (Friedrich, 2012). Assim, a atenção, por exemplo, a princípio regulada pelo meio, em que o outro apresenta à criança as coisas do mundo, é regulada pela criança que, em níveis progressivos, passa a direcioná-la e mantê-la para a apropriação de novas compreensões, ampliando suas significações. Ou seja, ao se constituir como mediada, a atenção assume o caráter de mediadora, passando a atuar na promoção do desenvolvimento de outras funções.

Concorre, nesse processo, a linguagem, função mediadora por excelência, visto constituir-se como instrumento psicológico no acesso do sujeito à cultura, via interações que empreende. Segundo Friedrich (2012), o instrumento psicológico teria duas qualidades que, de maneira dialética, o constituem: é mediatizado, por voltar-se, a um só tempo, para a regulação do social e do próprio sujeito que realiza a ação e, por isso mesmo, é mediatizante. É por este motivo que interessa à psicologia analisar os usos dos instrumentos psicológicos, dada sua origem social e porque, consequentemente, carregam em si qualidades dessas interações que constituirão a vida psíquica do sujeito (Friedrich, 2012). Reside nesta ideia a importância atribuída à escola, como promotora do acesso a conhecimentos e modos de pensamento e relações que se constituirão no sujeito como instrumentos psicológicos a serviço do desenvolvimento - no caso que nos interessa - alunos no período da adolescência.

Tomando o exemplo da palavra escrita e alinhando-o ao tema das pesquisas que inspiram este artigo, uma frase pichada na parede, como instrumento psicológico, é portadora não só dos significados que

\footnotetext{
2 A Base Nacional Curricular Comum (BNCC) é um documento normativo para as redes de ensino, aprovado em 2017 com orientações para ser implementada até 2020; ainda é objeto de discussão e demanda aprovação de alguns dos itens e propostas.
} 
quer comunicar, mas também de relações sociais apropriadas pelos jovens (Takara, 2016). Nesse sentido, concordamos com Friedrich (2012, p. 62) quando afirma que "[...] é a natureza social dos instrumentos psicológicos que se torna um dos objetos privilegiados da psicologia, pois se busca compreender quais são os objetos que adquirem essa função, em qual época e de que modo". Ou seja, a ação de um instrumento sobre si mesmo ou sobre o outro o constitui atividade mediatizante enquanto meio mobilizado para atingir o resultado que se deseja. Caberia questionar: em que medida os conhecimentos ensinados ou as situações vivenciadas na escola se constituem em atividades mediatizantes, que necessariamente mudam o curso do desenvolvimento?

Da perspectiva teórica aqui adotada, entende-se que, quanto maior o acesso a novos conhecimentos, relativos às coisas do mundo empírico ou teórico ou ainda às normas e valores da cultura, melhor a atuação das funções psicológicas, que a cada nova aquisição produzem novas relações, ampliando as formas de o sujeito ver e pensar o mundo; ou seja, maiores as possibilidades de significação e, por conseguinte, de desenvolvimento. Entretanto, se esse acesso não estiver disponível aos jovens, restringem-se suas possibilidades de ações futuras. Exemplo preocupante desta questão são os resultados das avaliações oficiais dos estudantes do Brasil, que revelam que a maioria não domina os conhecimentos básicos de língua portuguesa ou matemática.

Considerando o papel central da linguagem na mediação do desenvolvimento das funções psicológicas superiores, via significações do vivido e do pensado, parece dramática a situação da escola no que concerne ao cumprimento de seu papel sócio-político em relação às gerações atual e futura.

É na escola, cuja função privativa é a transmissão dos conhecimentos socialmente elaborados pela cultura, que o desenvolvimento da criança e do jovem pode alcançar níveis muito mais elevados no que concerne ao seu funcionamento psíquico. Isto porque, nesse momento, o sujeito passa a ter contato com conhecimentos formais, conceitos, princípios explicativos, novos modos de representação e explicação da realidade que exigem, por sua vez, novos modos de compreender e pensar do sujeito. Essa demanda do meio promove novas relações ou nexos entre as funções psicológicas que conferem ao sistema psicológico maior qualidade quanto às possibilidades de ação e pensamento. Segundo Vigotski (1930/2006), é no final da infância e início da adolescência que se desenvolve uma função psicológica, justamente como resultado das relações entre as demais funções referidas, de grande importância para a aprendizagem dos conhecimentos escolares e para o desenvolvimento do sujeito: o pensamento por conceito.

Essa função permite ao sujeito pensar de modo abstrato, sem qualquer referente do mundo empírico, pensamento exigido para a aprendizagem de conteúdos da matemática, da física, da química, da língua, enfim. Também é o pensamento por conceito, de natureza complexa e abstrata, que possibilita o desenvolvimento do pensamento crítico como capacidade de perceber e conceber o mundo como realidade ampliada e enxergar as condicionantes de fatos observados na atualidade, identificando sua historicidade, ou seja, suas origens e suas causas. Os conhecimentos, uma vez apropriados, se transformam em meios para o agir e o pensar do sujeito, podendo ser pensados como instrumentos psicológicos em seu caráter mediatizante, na medida em que passam a agir, internamente, a um só tempo, em direção ao próprio sujeito e em direção ao meio, consolidando novas formas de pensar e agir e se abrindo a novas apropriações. Então, possibilitam ao sujeito se libertar do mundo empírico, visto carregar consigo os meios para agir e pensar sobre a realidade (Souza, 2016a, 2019).

Esse processo de desenvolvimento do sistema psicológico equivale à conscientização como capacidade de compreender a si próprio na relação com o mundo, com o outro e com suas relações. Contudo, para que se efetive, ele requer o domínio de códigos da cultura em suas formas mais elaboradas, tais como a língua falada e escrita, as fórmulas matemáticas e os modos de raciocínio que envolvem os conhecimentos da física, das artes, da política, da economia. Enfim, é o que, para Vigotski (1935/2010), representaria o 
desenvolvimento ideal, entendido como ao alcance de todos os indivíduos, visto tratar-se da apropriação das conquistas da cultura humana.

Ocorre que a escola não tem investido na implementação de práticas pedagógicas que favoreçam o desenvolvimento das funções psicológicas superiores, como a atenção voluntária ou autorregulada, a linguagem como modo de expressão e comunicação, a memória mediada, a imaginação e o pensamento por conceito possíveis por meio da reflexão construída a partir de perguntas e não de respostas prontas. Ela deve investir em acesso a novas expressões linguísticas, novas tipologias textuais e não em cópias de textos da lousa ou de atividades que envolvem seguir procedimentos fechados e chegar a respostas únicas. A escola, em sua grande maioria, continua a desenvolver um ensino que se centra na memorização e reprodução, mantendo a concepção de que, uma vez alfabetizada, a criança ou jovem prosseguirá, naturalmente, aprendendo os conteúdos escolares independentemente de sua complexidade (Souza, 2016b).

Esse modo de ensinar alija o sujeito de alcançar novos modos de pensar e agir, impedindo-o de aceder a outros níveis de funcionamento psicológico e de se tornar autônomo para aprender e dominar novos conhecimentos. Radica nesta compreensão a preocupação que temos com os estudantes que cursam o Ensino Fundamental II, cujo currículo se organiza em torno do ensino de conteúdos complexos, que exigem o pensamento por conceito para sua apropriação (Souza, 2016a).

Ainda sobre o papel da escola, merece destaque o modo como Vigotski (1925/2007) compreende a relação entre a aprendizagem e o desenvolvimento. Para o autor, embora se tratem de processos dialéticos em que ambos se imbricam na produção de novas possibilidades de ação e pensamento, a aprendizagem estaria um passo adiante, visto ser um meio de acesso à cultura, cuja apropriação põe em curso o desenvolvimento e esse, ao mesmo tempo em que se produz enquanto desenvolvimento, gera novas possibilidades de aprendizagem que, ao se efetivarem, resultam em desenvolvimento. É dessa concepção que deriva a aposta que fazemos na escola como fomentadora do desenvolvimento do sujeito.

\section{A escola como produtora da desigualdade}

São várias as avaliações que medem o desempenho dos estudantes da Educação Básica brasileira e atestam as diferenças de desempenho entre os alunos das redes privada e pública de ensino. Uma delas é o Programme for International Student Assesment (PISA) - da Organização para a Cooperação e desenvolvimento Econômico - que, em 2019, avaliou uma amostra de 10.691 estudantes, sendo 1.381 de escolas privadas e 9.310 de escolas públicas. Os resultados colocam o Brasil com nota entre as mais baixas do mundo nas áreas avaliadas, ocupando o $70^{\circ}$ lugar. Entretanto, a avaliação também escancara a diferença de desempenho entre os alunos de escolas particulares e públicas. Em áreas como leitura e ciências, por exemplo, os alunos de escolas particulares ficam em $11^{\circ}$ e $23^{\circ}$ lugares, respectivamente. Já as avaliações dos alunos de escolas públicas nas mesmas áreas os colocam em $62^{\circ}$ lugar.

Outro importante indicador da qualidade da Educação Básica no Brasil é o Índice de Desenvolvimento da Educação Básica (IDEB), que utiliza uma escala de 0 a 10. Desenvolvido pelo Instituto Nacional de Pesquisa Educacional Anísio Teixeira (INEP), órgão do Ministério da Educação, o IDEB sintetiza em um único indicador duas dimensões para aferir a qualidade da educação: o fluxo, que representa a taxa de aprovação dos alunos, e o aprendizado, que corresponde aos resultados dos estudantes em uma avaliação do Sistema de Avaliação da Educação Básica (SAEB) aferido pela prova Brasil (que avalia a educação pública) e a Avaliação Nacional da Educação Básica do SAEB que inclui as escolas particulares.

Em 2019, os resultados do IDEB mostram o abismo existente entre o desempenho dos estudantes das redes privada e pública de ensino, conforme se observa nos dados a seguir. Observe-se esta afirmação em

4 números em cada um dos níveis de ensino: anos iniciais ( $1^{\circ}$ ao $5^{\circ}$ ano do Ensino Fundamental): rede pública: 
aprendizagem $(6,02)$ - fluxo $(0,94)$ - IDEB $(5,7)$, rede privada: aprendizagem $(7,18)$ - fluxo $(0,99)$ - IDEB $(7,4)$; anos finais ( $6^{\circ}$ ao $9^{\circ}$ ano do Ensino Fundamental): rede pública: aprendizagem $(5,1)$ - fluxo $(0,89)$ - IDEB $(4,6)$, rede privada: aprendizagem $(6,61)$ - fluxo $(0,97)$ - IDEB $(6,4)$; Ensino Médio: rede pública: aprendizagem $(4,54)$ - fluxo $(0,86)$ - IDEB $(3,9)$, rede privada: aprendizagem $(6,61)$ - fluxo $(0,97)$ - IDEB $(6,0)$.

Nota-se que, quanto mais avançam os anos da Educação Básica, mais aumenta a diferença de desempenho, visto que a aprendizagem diminui, e o fluxo que indica a reprovação aumenta. Ou seja, enquanto nos anos iniciais a aprendizagem dos alunos da rede pública atinge 6,02 e o fluxo 0,94 (indicando 6 reprovações a cada 100 alunos), nos anos finais da Educação Básica - Ensino Médio -, a aprendizagem é de 4,84 e o fluxo de 0,86 (14 reprovações). Como pode a aprendizagem diminuir após anos de escolaridade? Esse é um paradoxo a ser enfrentado e superado.

Esses dados também deixam entrever que, de todos os níveis, o Ensino Médio - cujos anos finais da Educação Básica têm a função de preparar os estudantes para a continuidade dos estudos no ensino superior ou para ingressarem no mercado de trabalho - é o que mais necessita de investimentos e de políticas públicas capazes de promover a superação destas condições desiguais, visto que o IDEB das escolas privadas é praticamente o dobro do das escolas públicas.

No entanto, pontua-se que, conforme se afirmou nas páginas precedentes, essa condição da escolarização brasileira repercute as desigualdades históricas no país e o que se quer defender neste texto é a urgência de se assumir educação como lugar de luta e superação das desigualdades.

Libâneo (2012, p. 13), refletindo sobre o papel da escola na transformação da realidade social, defende a existência de um "[...] dualismo perverso da escola pública brasileira". Segundo suas observações, haveria uma escola do conhecimento, destinada ao atendimento dos ricos, e uma escola do acolhimento social, voltada aos pobres.

A partir desta premissa, é possível pensar que, aos menos favorecidos, se reservaria a possibilidade de acessar os espaços, de se manter nas salas de aula, de ter contato com os pares, de obter alguns materiais, de acessar a merenda e aprender conhecimentos básicos de leitura e escrita. Mas não Ihes seria acessível o mais importante legado da humanidade: o conhecimento escolarizado com sua característica complexa capaz de promover o desenvolvimento de funções psicológicas superiores elevadas, conforme apontamos no item precedente (Souza, 2019).

Este dualismo perverso que tem contribuído para a produção da desigualdade no Brasil tem suas raízes, segundo o autor, na política neoliberal que tem sido operada no país e servido de aporte à instalação de movimentos pela educação que reforçam e sustentam a baixa qualidade do ensino ofertado à maioria dos brasileiros.

No documentário "Nunca me sonharam", de Rhoden (2017), cuja abertura apresenta o Art. 205 da Constituição Federal - que coloca a educação como direito de todos e dever do Estado e da Família, e visa ao pleno desenvolvimento da pessoa para o exercício da cidadania e do trabalho - um jovem editor de classe pobre diz que "[...] a ideia da meritocracia é ótima, mas ela é uma desculpa muito boa para não se ter de resolver alguns problemas, pois há uma corrida para se chegar ao topo do prédio, só que o rico sai do $3^{\circ}$ andar, de elevador, e o pobre sai do subsolo, e vai de escada". Isso ocorre ainda que ambos tenham passado pela educação básica, da qual uma parte - o Ensino Fundamental - é modelo de superação da desigualdade no Brasil no que concerne ao número de crianças e jovens atendidos.

Quer nos debrucemos sobre este segmento de ensino, quer avancemos para o Ensino Médio, ainda que este último tenha números vergonhosos no que concerne à frequência e permanência de alunos, o que se sobressai é a diferença de desempenho: conforme apontado na introdução, uma pequena parcela dos 
egressos da escola pública domina conhecimentos básicos de língua portuguesa e matemática³ ${ }^{3}$ conhecimentos fundamentais ao desenvolvimento do psiquismo e consequente domínio de conhecimentos mais elaborados e complexos pelos sujeitos.

Qual a razão de tal diferença, se o currículo no Brasil é o mesmo para todo o sistema de ensino, tanto de escolas públicas quanto de privadas? O que estaria na base do baixo desempenho dos alunos de escolas públicas? Por que a superação da desigualdade promovida pela universalização do Ensino Fundamental e a ampliação do número de vagas no ensino médio e superior não resultam em melhores condições de vida em sociedade para uma parcela maior da população?

Arretche (2015) chama a atenção para o tratamento que pesquisadores e gestores de políticas públicas têm dado à questão da desigualdade - por vezes como uma condição que, uma vez superada, é naturalizada e não se volta mais a ela. A autora defende que é preciso tomá-la no plural, e observar seu movimento, e então propõe que se considerem as "trajetórias das desigualdades", visto que esta não se manifesta como única, mas representa e repercute um conjunto de situações que a caracteriza, exatamente o que justifica falar em trajetória.

[...] o termo 'desigualdade' é excessivamente abstrato. No mundo social, existem múltiplas desigualdades: entre ricos e pobres, entre mulheres e homens, entre categorias de raças, as quais, por sua vez, se manifestam na renda, no acesso a serviços, na participação política. [...] entender a desigualdade requer examinar suas múltiplas dimensões (Arretche, 2015, p. 6).

Essa explicação permite uma primeira aproximação à compreensão da questão colocada acima: a desigualdade de "acesso à escola" fundamental foi superada, com a criação de vagas para todos, mas não a de "acesso a uma educação de qualidade". E então a trajetória muda: é preciso compreender as desigualdades produzidas na oferta da qualidade da educação nas escolas e criar formas de superá-las via políticas públicas.

Juntar a explicação de Libâneo (2012) a esta questão nos parece plausível para continuar a reflexão: ainda que todos estejam na escola de Ensino Fundamental, há diferenças no modo como funcionam as escolas de ricos e as de pobres. O autor, com base no exame das políticas educacionais nos últimos 20 anos no Brasil, analisando suas raízes ou princípios, sintetiza o que tem caracterizado a educação básica no país como "dualismo perverso", visto sua eficiência em produzir e manter desigualdades sociais. Os vínculos de tal política remetem à reforma do ensino inglês nos anos 1980, de base neoliberal, e destaca que essa política teria relação estreita com uma série de acordos internacionais, na esteira do movimento "Educação para Todos" ${ }^{4}$, que constituem um pacote do Banco Mundial para a pretensa melhoria da qualidade da educação (Souza, 2019).

Entendemos, corroborando as ideias de Libâneo (2012), que políticas educativas criadas a partir de interesses de órgãos internacionais, mediadas pelo Banco Mundial, sobre o que seria ou deveria ser a qualidade da educação em nosso país - sem considerar a complexidade que caracteriza o público da escola pública, e assentadas em bases neoliberais - se constituem solo fértil para a diversidade e os antagonismos de posições sobre os objetivos e as finalidades da educação escolar no Brasil. Ou seja, quanto menos clareza, maior a alienação e tendência a naturalizar o que na verdade é histórico e cultural (Souza, 2019).

${ }^{3}$ Segundo dados do SAEB realizado pelo INEP, órgão do Ministério da Educação responsável pela avaliação que envolve mais de 70 mil escolas do Brasil e avalia a Educação Básica em Português e Matemática, o desempenho dos estudantes está estagnado abaixo do esperado em todos os níveis avaliados (Ministério da Educação, 2021, online).

4 Segundo o autor, este movimento teve como marco a "Conferência Mundial sobre Educação para Todos", realizada em Jomtien, na Tailândia, em 1990, sob os auspícios do Banco Mundial, do Programa das Nações Unidas para o Desenvolvimento (PNUD), do Fundo das Nações Unidas para a Infância (UNICEF) e da Organização das Nações Unidas para a Educação e Cultura (UNESCO)" (Libâneo, 2012, p. 12). 
A infinidade de funções que ela teria segundo o que circula no meio educacional impacta sobremaneira as significações sobre e com a escola. Essas significações derivam de inúmeras propostas, em geral antagônicas ou contraditórias, que envolvem desde um clamor a um retorno ao que seria uma pedagogia "tradicional", com centralidade no ensino de conteúdos dispostos em organizações fechadas e sem abertura a inserção de variações decorrentes do contexto, a um enfoque em assistência e acolhimento às populações que frequentam a escola pública como forma de enfrentar a desigualdade (Libâneo, 2012).

Nos parece que a questão a se colocar em um artigo que se propõe a discutir a educação da perspectiva da Psicologia Cultural é sobre o impacto no desenvolvimento de crianças e adolescentes dessas políticas centradas em visões polarizadas acerca do que deve ser a educação, com variantes ajustáveis aos menos favorecidos ou mais favorecidos.

Citado pelo próprio Libâneo (2012), o educador e pesquisador português, Antônio Nóvoa, já em 2009, chamava a atenção para o perigo que pode envolver uma educação com "velocidades" diferentes, desenvolvidas em escolas voltadas a públicos e objetivos distintos. Para os pobres assumiria como função principal o acolhimento social, com ênfase na formação cidadã e na participação; e para os ricos, com enfoque na aprendizagem, no domínio de diferentes linguagens e tecnologias.

A preocupação de Nóvoa pode ser pensada da perspectiva dialética que caracteriza os fenômenos no tipo de análise que nos interessa: a fala do jovem editor que abre este item, de que na corrida ao topo do prédio, os ricos saem do $3^{\circ}$ andar, de elevador e o pobre do subsolo, de escada, somada aos cortes de investimento e aos resultados de avaliações da educação básica, parecem indicar que a educação no Brasil não somente tem conseguido produzir desigualdade, mas a tem perpetuado. Até os dias atuais, os horizontes são temerários, acepção que nos conduz a identificar um projeto neoliberal que visa beneficiar poucos.

\section{As artimanhas da desigualdade: a dificuldade em lidar com as diferenças e o diferente}

O último Censo Escolar, publicado em 2018, revela que havia 48,6 milhões de alunos matriculados na Educação Básica no Brasil. Desse total, somente 18,3\% estavam na rede privada de ensino, ou seja, a imensa maioria das crianças e jovens, de 0 a 17 anos no país $(81,7 \%)$ frequentava a rede pública de ensino (Instituto Nacional de Estudos e Pesquisas Educacionais Anísio Teixeira, 2018).

O exame da questão permite identificar contradições em camadas: a escola feita para acolher, sob o mote do acolhimento, exclui justamente pela "repulsa à diferença" (Cunha \& Dazzani, 2016). Ela foi pensada para acolher um tipo de criança e jovem que se conforma às regras e normas e se submete ao que a instituição Estado, que deveria garantir direitos, oferece, em geral, o que seu público não necessita ou deseja. Como atender aos quase 40 milhões de estudantes garantindo seus direitos de acesso aos bens da cultura, bens esses essenciais ao desenvolvimento de funções psicológicas complexas, como o pensamento por conceito, por exemplo? Como desenvolver o pensamento necessário à apropriação de conhecimentos complexos, exigidos para o domínio de linguagens tecnológicas, de conceitos de física, química e matemática? Esses conhecimentos, por sua vez, constituem-se mediatizantes do processo de desenvolvimento do sujeito, que não cessa, ao contrário, Ihe permite acessar novos conhecimentos, desenvolver novas relações e pensamentos. Assim, esse estudante pode vislumbrar condições de vida diferentes das que vive no presente (Souza, 2016a, 2019).

\section{Um breve relato de vivência na escola}

O relato a seguir, retirado de um Diário de Campo, reporta-se ao Ensino Fundamental II de uma escola pública em uma grande cidade do interior do Estado de São Paulo. É parte de uma intervenção realizada por uma psicóloga-doutoranda que estuda as emoções na escola. 
Entrei na turma do $6^{\circ}$ ano para me apresentar contando minha história em terceira pessoa. Enquanto contava, os alunos se entreolhavam, sorriam, cochichavam, estavam atentos. Ao terminar, um pedido: agora me contem a história de vocês, quero conhecê-los! O que escutei foi uma avalanche de sofrimento, de dor, de tristeza em forma de experiências, daqueles que eu considerava ainda crianças. Aqueles que não quiseram contar a sua história, o meu interesse em conhecê-los mobilizou choros, tentativas de se esconder atrás da mochila e do silêncio. Mas, desse silêncio na fala oral surgiu a escrita, um outro jeito de se comunicar, de manifestar querer um espaço para ser ouvido. Os choros, reações de raiva, de medo, de diferentes sentimentos, entretanto, perduraram. No decorrer de meio semestre, ao chegar na escola, já havia alunos me esperando no corredor, chorando. Ao entrar na sala, antes de me cumprimentarem, já ouvia pedidos para 'fazer uma roda e conversar' e havia ainda, aqueles que me procuravam após as minhas intervenções para conversar, muitos deixando de aproveitar o intervalo (Jesus, 2020, p. 6).

Qual a razão das manifestações de choro frequentes e recorrentes naquele grupo de estudantes? Reportando a outras situações vividas pelos integrantes do grupo de pesquisa, não encontrávamos algo semelhante. Instigados a compreender o fenômeno e buscando contribuir para superar aquela condição de sofrimento vivido pelos estudantes, iniciamos um projeto de contação de histórias e, ao longo das atividades, outras manifestações foram sendo observadas. Entre elas, notou-se "[...] discussões em tons agressivos desencadeadas por motivos banais, brigas, por vezes, com agressões físicas e ofensas verbais, recusas em conversar ou olhar para a psicóloga, quase todos os episódios acompanhados de choro" (Jesus, 2020, p. 12). "Ainda que o fenômeno naquele momento se mostrasse obscuro, iniciava-se o desvelamento de algumas contradições que sustentavam sua existência concreta" (Jesus, 2020, p. 12), o que nos possibilitou questionar: por que as emoções eram prevalentes na escola, tornando-se o foco de preocupação dos educadores? Como atuar, enquanto psicólogos escolares, de modo a potencializar os recursos dos alunos para o conhecimento da própria emoção?

Nossas tentativas de diálogo, de reflexão com o grupo, se mostravam infrutíferas, e observamos que eles só queriam poder expressar o que estavam sentindo e, com isso, se sentiam acolhidos em nossos encontros.

Concomitantemente, professores e equipe gestora da escola relatavam a dificuldade em lidar com as situações, em conseguir que os alunos se apropriassem do conhecimento ensinado, uma vez que a prevalência das emoções emperrava a concentração e a atenção dos estudantes. Frente a estes momentos, as decisões e ações dos docentes visavam ao controle das emoções, como dizer aos alunos que parassem de chorar e/ou encaminhando-os à gestão (Jesus, 2020, p. 13).

Os docentes, então, passaram a relacionar o choro dos alunos com nosso trabalho, sugerindo que as ações que desenvolvíamos mobilizavam o choro dos alunos.

Esses acontecimentos nos revelaram não apenas os conflitos que existiam nas relações, mas, sobretudo, que novos conflitos eram produzidos quando predominavam as emoções, principalmente nas relações entre professores e alunos. Isso porque não se sabe lidar com as emoções ou, melhor dizendo, nas significações dos docentes, a escola não é lugar de emoções, ainda que ela se signifique como lugar de acolhimento.

Segundo Sawaia (2009), todo sofrimento é social e a qualidade "ético-política" atribuída ao sofrimento implica compreendê-lo vinculado a servidão, a passividade e é uma forma de se posicionar politicamente, uma vez que esse sofrimento é atravessado pela classe social. O 'ético-político' traz em sua concepção o fato de o sujeito estar submetido ao poder do outro, que define o seu lugar e sua possibilidade de mobilidade na sociedade. Qual o lugar desses jovens que sequer conseguem compreender o que sentem e porque sentem? Que implicações essa situação vivida tem para o seu desenvolvimento? Como conviver com a tristeza a que estão submetidos? Como aprender nessa condição?

Para Vigotski (1934/2009) toda ação é motivada, tem em sua base o afetivo-volitivo e as emoções são 8 parte essencial da atividade de aprendizagem. Sawaia (2009) compreende a afetividade como indissociável das 
funções psicológicas superiores, podendo ser definida como a capacidade humana de afetar e ser afetado, e correspondente às emoções e sentimentos. A emoção é um afeto mais imediato e momentâneo, desperto por algo específico, enquanto o sentimento seria emoção elaborada, significada, mais duradoura e que não se liga a especificidades. Nesse sentido, a emoção/sentimento pode ser entendida como função psicológica superior, visto ser mediada pela cultura. Segundo Sawaia (2000, p. 14) "[...] as emoções também são funções mediadas, são sentimentos humanos superiores, pois até o próprio organismo reage a significados de forma que as sinapses cerebrais são mediadas socialmente".

Entretanto sua manifestação, vista como "problema" que atrapalha a aprendizagem e a convivência na escola, que transforma singularidades sensíveis, espontâneas, efusivas, introspectivas, em "choronas", "descontroladas", "agressivas", "depressivas", "esquisitas", concorre na produção de estigmas. Ao contrário de reconhecer as diferenças e tomá-las em seu potencial nas interações promotoras de desenvolvimento, marcam os sujeitos e geram mais conflitos, fazendo da escola um lugar que exclui as diferenças. Eis a contradição manifesta pela escola do acolhimento que não acolhe, justamente por não se reconhecer nesta função, visto que tradicionalmente tem sido postulada como lugar do ensino e da aprendizagem.

Muitas são as questões que necessitariam ser tratadas para uma análise das razões que estariam na base desse funcionamento da escola pública. Essas questões vão além das políticas educacionais e da história da educação no Brasil. Como aponta Libâneo (2012, p. 14) "[...] o próprio campo educacional, nos âmbitos institucional, intelectual e associativo, está longe de obter um consenso mínimo sobre os objetivos e as funções da escola pública na sociedade atual".

Entretanto, o que se buscou com essas reflexões foi problematizar os efeitos da educação oferecida nas escolas públicas na promoção do desenvolvimento de crianças e adolescentes que têm, na escola, uma das pouquíssimas chances para acessar e se apropriar de recursos da cultura, sobretudo dos conhecimentos formais e complexos cujo ensino é privativo da instituição escolar. Antes de passar ao último item deste artigo, cabe asseverar que se, como afirma Arretche (2015), em países subdesenvolvidos, como é o caso do Brasil, a desigualdade nunca é superada mas muda de trajetória, a luta a ser empreendida é pela instauração de políticas de Estado capazes de mapear e agir, permanentemente, no combate à desigualdade, e não de políticas de governo que, de tempos em tempos, mudam seu foco e elegem as questões que melhor se adequam a objetivos pontuais, por vezes questionáveis.

\section{Considerações Finais}

Neste momento em que finalizo esta reflexão completamos um ano de isolamento social e fechamento das escolas em decorrência da COVID-19, pandemia que assolou o mundo em 2020, obrigando-nos a permanecer em nossas casas como forma de evitar a propagação do vírus. Nesse tempo, muitas e várias iniciativas foram desenvolvidas pelas escolas de modo a continuar favorecendo a aprendizagem dos estudantes e evitar que se perdesse o ano escolar. As escolas privadas agiram rapidamente, investiram em equipamentos e treinamento de professores, e os estudantes, por sua vez, munidos de tecnologia suficiente para acessar as aulas oferecidas pelas escolas, conseguiram seguir estudando, ainda que não de maneira ideal ou do modo desejado. Já as escolas públicas tiveram muitas e inúmeras dificuldades, a começar pela demora em estabelecer novas formas de ensinar e acessar os estudantes. Houve um esforço enorme de gestores e educadores, mas, passado mais de meio ano letivo, cerca de $50 \%$ dos estudantes não estavam acompanhando as atividades, a grande maioria por não dispor de equipamentos tecnológicos para acessar as aulas. Logo, a diferença de desempenho que já era grande, agora se amplia e escancara a desigualdade social como grande barreira para o desenvolvimento de crianças e jovens. As consequências do período fora da escola não param por aí, a queda no número de matriculas no Ensino Médio no ano de 2021 indica a altíssima evasão de jovens 
da escola, pondo em risco as possibilidades de superação das condições desiguais que vivenciam. O desafio que as escolas têm se colocado é trazer esses jovens de volta para a escola.

O que define ou caracteriza a complexidade das questões desenvolvidas neste texto é o fato de a escola se configurar como espaço em que interagem sujeitos singulares, com valores, crenças, necessidades, interesses, histórias de vida e objetivos diferentes, conferindo aos cenários e contextos educacionais o caráter de heterogeneidade e diversidade. Entretanto, complexo não é sinônimo de problemático ou indesejável, mas de potência de desenvolvimento, mediado pela diversidade.

Em consonância com os autores que apoiam a reflexão proposta neste artigo, entendo o meio ambiente como condição do desenvolvimento, considerando-o como fonte em cujas interações o sujeito se apropria da cultura. Ocorre que o sujeito se apodera da cultura e a desenvolve em várias direções, podendo seguir rumo ao desenvolvimento cada vez mais complexo, conquistando possibilidades de autoria e liberdade, ou orientar-se em direções que o impedem de acessar níveis mais elevados de pensamento, mantendo-se em condições de submissão e padecimento, a mercê de condições materiais precarizadas e produtoras de sofrimento, sem poder visualizar caminhos ou saídas possíveis. A escola é um meio favorável para transformar essas condições, na medida em que investe na reflexão sobre o que se sente, se vive, se percebe em relação às próprias experiências e aquelas imaginadas por crianças e adolescentes que frequentam a escola pública.

Se as condições que caracterizam a escola pública brasileira na atualidade revelam problemas grandiosos, a educação, se voltada ao oferecimento dos símbolos da cultura, pode e deve promover novos horizontes para as crianças e jovens. Ela deve oferecer experiências que possibilitam trajetórias diferentes para cada sujeito, viabilizadas pelo universo de significações possíveis, que deve caracterizar o mundo da cultura ao se referir às possibilidades que estão permanentemente abertas aos seres humanos. Humanos, que são e sempre serão diversos.

\section{References}

Arretche, M. (2015). Trajetórias das Desigualdades: como o Brasil mudou nos últimos cinquenta anos. Universidade Estadual Paulista.

Cunha, E. O., \& Dazzani, M. V. M. (2016). Da repulsa da escola à diferença: historicizando raízes, perspectivando saídas. In M. V. M. Dazzani \& V. L. T. Souza (Orgs.), Psicologia Escolar Crítica: teoria e prática nos contextos educacionais (pp. 57-75). Átomo e Alínea.

Friedrich, J. (2012). Lev Vigotski - mediação, aprendizagem e desenvolvimento: uma leitura filosófica e epistemológica. Mercado das Letras.

Instituto Nacional de Estudos e Pesquisas Educacionais Anísio Teixeira. (2018). Censo Escolar 2017: notas técnicas. Instituto Nacional de Estudos e Pesquisas Educacionais Anísio Teixeira. http://inep.gov.br/censo-escolar

Jesus, J. S. (2020). As histórias que contamos de nós: mobilizando a imaginação e as emoções de estudantes do Ensino Fundamental /l (Tese de doutorado não-publicada). Pontifícia Universidade Católica de Campinas.

Libâneo, J. C. (2012). O dualismo perverso da escola pública brasileira: escola do conhecimento para os ricos, escola do acolhimento social para os pobres. Educação e Pesquisa, 38(1), 13-28. https://doi.org/10.1590/S151797022011005000001

Ministério da Educação (Brasil). (2021). Relatório do Sistema Nacional de Avaliação da Educação Básica (SAEB) - ciclo 2019. Ministério da Educação. www.inep.gov.br

Rhoden, C. (Diretor). (2017). Nunca me sonharam [Documentário]. Maria Farinha Filmes.

Sawaia, B. B. (2000). A emoção como locus de produção do conhecimento: uma reflexão inspirada em Vygotsky e seu diálogo com Espinosa. Anais da III Conferência de Pesquisa Sócio-Cultural, Campinas. https://www.unifal-mg.edu.br/ humanizacao/2017/11/11/a-emocao-como-locus-de-producao-do-conhecimento-uma-reflexao-inspirada-em-vygotskye-no-seu-dialogo-com-espinosa/

Sawaia, B. B. (2009). Psicologia e desigualdade social: uma reflexão sobre liberdade e transformação social. Psicologia \& Sociedade, 21(3), 364-372. https://doi.org/10.1590/S0102-71822009000300010 
Souza, V. L. T. (2016a). Arte, imaginação e desenvolvimento humano: aportes à atuação do Psicólogo na escola. In M. V. M. Dazzani \& V. L. T Souza (Orgs.), Psicologia Escolar Crítica: teoria e prática nos contextos educacionais (pp. 77-94). Alínea e Alínea.

Souza, V. L. T. (2016b). Contribuições da Psicologia à compreensão do desenvolvimento e da aprendizagem. In V. L. T. Souza, A. P. Petroni, \& P. C. Andrada (Orgs.), A Psicologia da arte e a promoção do desenvolvimento e da aprendizagem: intervenções em contextos educativos (pp. 11-28). Edições Loyola.

Souza, V. L. T. (2019). A pesquisa-intervenção como forma de inserção social em contextos de desigualdade: arte e imaginação na escola. Psicologia em Revista, 25(2), 689-706. https://doi.org/10.5752/P.1678-9563.2019v25n2p689-706

Takara, L. M. (2016). "Nóis pixa voces pinta, vamu ve quem tem mais tinta": a mediação do espaço físico e social na promoção do desenvolvimento da imaginação de adolescentes do Ensino Médio [Dissertação de mestrado não-publicada]. Universidade Católica de Campinas.

Vigotski, L. S. (2006). Obras Escogidas IV - Paidología del adolescente: problemas de la psicología infantil (2a ed.). Visor y A. Machado Libros. (Originalmente publicado em 1930).

Vigotski, L. S. (2007). A formação social da mente (J. C. Neto, L. S. M. Barreto, \& S. C. Afeche, Trad.; 7a ed.). Martins Fontes. (Originalmente publicado em 1925).

Vigotski, L. S. (2009). A construção do pensamento e da linguagem (P. Bezerra, Trad.; 2a ed.). Martins Fontes. (Originalmente publicado em 1934).

Vigotski, L. S. (2010). Quarta aula: a questão do meio na pedologia. (M. P. Vinha, Trad.). Psicologia USP, 21(4), 681-701. (Originalmente publicado em 1935). https://doi.org/10.1590/S0103-65642010000400003

Recebido: agosto 11, 2020

Versão final: fevereiro 24, 2021

Aprovado: abril 5, 2021 